\title{
Environmental and occupational respiratory diseases -1035. Isolation and purification of major allergenic protein of moth and rice weevil insect extracts
}

\author{
Mohd Adnan Kausar ${ }^{*}$, Waseem Ahmad Siddiqui \\ From 2nd WAO International Scientific Conference (WISC 2012) \\ Hyderabad, India. 6-9 December 2012
}

\section{Background}

The study was plan to isolate and purify the major allergenic protein from moth and rice weevil insect whole body extracts (WBEs).

\section{Methods}

For purification of allergenic proteins, crude insect WBEs were subjected to $80 \%$ ammonium sulphate precipitation, anion exchange column chromatography using DEAESephacel and fast protein liquid chromatography (FPLC) using Mono Q column.

\section{Results}

After $80 \%$ ammonium sulphate precipitation, most of the proteins were recovered in $80 \%$ precitable fraction, $58.4 \%$ in moth and $71.2 \%$ in rice weevil. However, the recovery in supernatant was low $6.1 \%$ in rice weevil and 14.4 in moth extract. In ELISA inhibition of both the insect WBEs, most of the allergenic activity was recovered in $80 \%$ ammonium sulphate precipitate fraction (80\% ppt). No allergenic protein bands were detected in the supernatants of both insect extracts. Molecular weights of allergenic proteins ranged from $10 \mathrm{kDa}$ in to $105 \mathrm{kDa}$.

When $80 \%$ ppt of both the insect extracts was subjected to anion exchange chromatography, three peaks were obtained in each extracts. FrI of both the purified insects induced significant inhibition of insects ELISA. FrII of both insects also produced some inhibition, FrIII failed to induce any inhibition. SDS-PAGE analysis of FrI revealed that it contains 13 proteins in moth and 10 protein bands in rice weevil. In immunoblot experiments, FrI showed only one allergenic protein of moth $(30 \mathrm{kDa})$ and three in rice weevil $(63 \mathrm{kDa}, 45 \mathrm{kDa}$ and $22 \mathrm{kDa})$.

On FPLC of FrI of moth and rice weevil extract, four fractions (FrIa, FrIb, FrIc and FrId) were obtained. Of the 4 fractions, FrIa of moth and FrIc of rice weevil showed maximum allergenic activity.In SDS-PAGE analysis of FrIa of moth and FrIc of rice weevil revealed protein bands of $30 \mathrm{kDa}$ and $45 \mathrm{kDa}$, respectively. Major allergenic proteins of moth extract identified in immunoblot experiments, corresponding to molecular weight $30 \mathrm{kd}$ was recovered in fraction moth-FrIa; in rice weevil extract major allergenic protein was recovered in fractions FrIc of molecular weight $45 \mathrm{kDa}$.

\section{Conclusions}

This purified protein may be used as a reference reagent for the standardization of insect extracts used for diagnosis and immunotherapy of allergic patients.

Published: 23 April 2013

doi:10.1186/1939-4551-6-S1-P34

Cite this article as: Kausar and Siddiqui: Environmental and occupational respiratory diseases -1035 . Isolation and purification of major allergenic protein of moth and rice weevil insect extracts. World Allergy Organization Journal 2013 6(Suppl 1):P34.

Department of Biochemistry, Jamia Hamdard, New Delhi, India 